\title{
Immunomodulation of Experimental Autoimmune Uveitis Using a Rat Anti Retinal S-Antigen Specific Monoclonal Antibody: Evidence for a Species Difference.
}

\author{
H.S. DUA, J. LIVERSIDGE and J.V. FORRESTER.
}

Aberdeen

\begin{abstract}
Summary
Experimental Autoimmune Uveitis (EAU) induced by retinal antigens, particularly S-antigen, forms a useful model of human chronic intraocular inflammation particularly endogenous posterior uveitis. It provides a means of assessing the efficacy of various agents used in the control of such inflammation. We induced an autoimmune uveitis and its associated pinealitis in Dunkin-Hartley guinea pigs and Lewis rats by inoculating them with bovine retinal S-antigen. In rats, induction of EAU but not of Experimental Autoimmune Pinealitis (EAP) could be prevented by the administration of $S$-antigen specific rat monoclonal antibody simultaneously with the S-antigen. Inhibition of EAU was accompanied by significantly raised levels of anti-S antibodies during the first two weeks post-immunisation. In contrast, the same monoclonal antibody failed to inhibit both EAU and EAP in guinea pigs. Immunocytochemical staining of rat tissues for lymphocyte subsets, monocytes and macrophages showed that eyes of monoclonal antibody treated animals contained no immunocompetent inflammatory cells unless they also had clinical signs of inflammation. In contrast, the inflammatory exudate in the pineal glands of both treated and untreated animals contained equal numbers of infiltrating lymphocytes and monocytes in the same relative proportions. These results indicate that the inhibitory effect of the monoclonal antibody S2.4.C5 is directed towards the effector arm of the immunemediated cytotoxic response. A possible mechanism by which the antibody may be preferentially inhibiting the inflammatory response in the eyes but not in the pineal glands of rats, is suggested.
\end{abstract}

Chronic intraocular inflammation is an important cause of ocular morbidity and visual loss particularly among young adults. Several exogenous and endogenous factors have been identified in the ætiology of such inflammation. ${ }^{1}$ However, in spite of intensive investigation, specific ætiological agent(s) have rarely been demonstrated, and associations with other systemic diseases have been shown in only $50 \%$ of cases. ${ }^{2-4}$ A large proportion of these cases present evidence of an immunological disturbance indicating that immune mechanisms are involved in initiating and/or establishing the chronicity of the disease and its tendency to recur. ${ }^{5-9}$ Experimental autoimmune uveitis (EAU) induced by retinal antigens, particularly $\mathrm{S}$-antigen is a useful animal model of chronic intraocular inflammation. Besides uveitis, S-antigen induces an inflammatory reaction in the pineal gland thereby demonstrating another link between the pineal gland and the eye. ${ }^{10-12}$ 
EAU has been used extensively in studying the ætiopathogenesis and pathology of chronic uveitis. ${ }^{13-18}$ It also provides a means of testing therapeutic agents and regimes that may be of value in the management of human uveitis. Immunomodulation of EAU using monoclonal antibodies to stimulate antiidiotypic antibodies is currently receiving much attention. ${ }^{19-21}$ De Kozak et al ${ }^{19}$ showed that the induction of EAU could be inhibited by the administration of an S-antigen specific monoclonal antibody simultaneously with the $\mathrm{S}$-antigen. They used a mouse anti-S monoclonal antibody in Lewis rats. In this heterologous system, it was suggested that the immunogenic and uveitogenic effects of S-antigen were inhibited via induction of anti-idiotypic responses. In the present study we used a rat anti-S monoclonal antibody, S2.4.C5, ${ }^{22}$ and tested its effect on EAU in (a) a heterologous system using Dunkin Hartley guinea pigs and (b) a homologous system using Lewis rats. We also studied the effect of the monoclonal antibody on experimental autoimmune pinealitis (EAP) in both these groups of animals. A possible mechanism of action of the monclonal antibody, other than by invoking an anti-idiotypic response, is suggested.

\section{Material and Methods}

Animals: The initial study was conducted in guinea pigs. Nine Dunkin-Hartley guinea pigs (weighing 600 - 800 grams each) were subdivided into a test group of five animals (Group 1) that received the monoclonal antibody plus antigen and a control group of four animals (Group 2) that received the S-antigen alone.

In the second experiment, twenty two female Lewis rats (180 to 250 grams each) were subdivided into three groups all of whom were immunised with retinal S-antigen. A test group of ten animals (Group 1) also received the monoclonal antibody. One control group of six animals received no further therapy (Group 2) while the second control group was inoculated with a nonspecific rat $\mathrm{IgG}$ in addition to the $\mathrm{S}$-antigen (Group 3).

Retinal S-antigen: Bovine retinal S-antigen was prepared as previously described ${ }^{23}$ except that the final purification of antigen was performed by high performance liquid chromatography on a TSK-DEAE column. The antigen purity was demonstrated as a single homogeneous band by silver staining on SDS polyacrylamide gel using the Pharmacia Phast system according to the manufacturer's instructions.

Monoclonal antibody to bovine S-antigen: A rat cell-line, S2.4.C5, was used to produce monoclonal antibody to bovine S-antigen. ${ }^{22}$ Antibody was collected as cell supernatant and purified using established methods on QEAE Sephadex. Some samples were

Table I Immunisation protocol

\begin{tabular}{|c|c|c|c|c|c|c|c|}
\hline Expt. & Group & No. & $\begin{array}{c}S-A g .^{*} \\
\text { (ug) }\end{array}$ & $\begin{array}{c}C F A^{* *} \\
(m l s)\end{array}$ & $\begin{array}{l}\text { Pertussist } \\
\quad(\mathrm{mls})\end{array}$ & $\begin{array}{c}\text { S2.4.C5t† } \\
(\mathrm{mls})\end{array}$ & $\begin{array}{c}\text { Rat IgG@ } \\
\text { (mls) }\end{array}$ \\
\hline \multirow{2}{*}{$\begin{array}{l}\text { Guinea } \\
\text { pigs }\end{array}$} & 1 & 5 & 50 & 0.25 & - & 2 & - \\
\hline & 2 & 4 & 50 & 0.25 & - & - & - \\
\hline \multirow[t]{3}{*}{ Rats } & 1 & 10 & 50 & 0.25 & 1 & 1 & - \\
\hline & 2 & 6 & 50 & 0.25 & 1 & - & - \\
\hline & 3 & 6 & 50 & 0.25 & 1 & - & 1 \\
\hline
\end{tabular}

* Bovine S-antigen (200 micro grams/ml in phosphate buffered saline (PBS) pH 7.4).

** Complete Freunds Adjuvant, H37Ra (Difco). The S-antigen and adjuvant were mixed and injected into the foot pad.

$\dagger$ B. pertussis organisms, suspension of $10^{10}$ cells $/ \mathrm{ml}$ in PBS injected intraperitoneally.

$\dagger \dagger$ Rat anti-S (Bovine) monoclonal antibody, S2.4.C5., $\mathrm{IgG}_{1}, 1 \mathrm{mg} / \mathrm{ml}$ in PBS given by intraperitoneal injection.

@ Non-specific rat IgG (Sigma), $1 \mathrm{mg} / \mathrm{ml}$ in PBS given intraperitoneally. 
further purified by affinity chromatography on Protein-A Sepharose, and shown to contain over $99 \%$ IgG by SDS-PAGE (Pharmacia Phast system).

Immunisation protocol: Eyes of all animals were examined by slit lamp biomicroscopy prior to immunisation to exclude any preexisting pathology. The animals were then immunised as described in Table I. Rats were tail bled after inoculation, and serum was stored at $-70^{\circ} \mathrm{C}$.

Clinical observation: All animals in both experiments were observed from day one post-inoculation. Clinical examination of the eyes with the slit lamp and direct ophthalmoscope was carried out after dilation of pupils with $1 \%$ cyclopentolate. The day of onset of uveitis, its severity and its course were noted. The severity of the inflammatory activity was graded on a scale of $0-4$ as described by Forrester et al. ${ }^{17}$ Rats were tail bled at weekly intervals until sacrificed and serum stored at $-70^{\circ} \mathrm{C}$.

Sample preparation: Guinea pigs were sacrificed on days $22 / 23$ post-inoculation. Both eyes and the pineal gland were obtained for examination. One eye was snap frozen in Tissue-TEK, OCT compound (Miles Scientific) by immersing in liquid arcton near its freezing point. The other eye was fixed in 3\% phosphate buffered glutaraldehyde and processed for electron and light microscopy. The pineal gland was fixed in acetic formal,saline and processed for light microscopy.

Rats were sacrificed at various time intervals, mostly around the peak of the inflammatory activity or soon thereafter. Animals that did not show any clinical disease were killed 28 to 30 days post-immunisation. Blood samples were collected and both eyes and the pineal gland were obtained for examination. One eye from each animal and half of the pineal glands from each group were snap frozen. The other eye and the remaining pineal glands were fixed in 3\% phosphate buffered glutaraldehyde and processed for electron and light microscopy.

Immunocytochemistry: Lymphocyte subpopulations were tested in inflammatory lesions in rat eyes using a panel of monoclonal antibodies (Table II). Frozen sections on chrome-alum gelatin coated glass slides were stained by hematoxylin and eosin and also by the immunocytochemical Alkaline Phosphatase Anti-Alkaline Phosphatase (APAAP) technique. Rabbit anti-mouse immunoglobulin (Dakopatts) was used as the secondary antibody and APAAP (mouse) complexes (Dakopatts) as the tertiary antibody. Semi-thin sections of glutaraldehyde fixed tissues, stained with toluidine blue and basic fuschin, were also used for histopathological study.

Antibodies to Retinal S-antigen: Antibody titres to retinal $S$-antigen were estimated using a standard ELISA technique ${ }^{24}$ modified for rat serum. Microtiter 96 well plates were coated with bovine $\mathrm{S}$-antigen (1 microg$\mathrm{ram} / \mathrm{ml}$ in $0.02 \mathrm{M} \mathrm{Tris} / \mathrm{HCl}$ buffer, $\mathrm{pH} 9)$, blocked with $0.5 \%$ bovine serum albumin, then incubated with the test sera. Bound antibodies were detected using peroxidase conjugated rabbit anti-rat immunogloblins (Dakopatts).

Table II Monoclonal markers used (Serotec):

Monoclonal markers used (serotec):

\begin{tabular}{llll}
\hline 1. & W3-25 & (CD4) & T-helper, macrophages, thymocytes. \\
2. & OX 8 & (CD8) & T-supressor/cytotoxic, N-K cells. \\
3. & OX 19 & (CD5) & Pan-T cells. \\
4. & OX 44 & & Pan-T cells. \\
5. & MARD 3 & B cells, (anti-IgD heavy chain). \\
6. & OX 39 & Interleukin 2 receptor. \\
7. & OX 6 & & DR/Ia monomorphic, (MHC class II). \\
8. & ED1 & & Monocytes and macrophages. \\
\hline
\end{tabular}




\section{Results}

\section{Guinea Pigs}

Clinical: All five guinea pigs in Group 1 (monoclonal antibody plus S-antigen) had signs of uveitis by day 10 and by day 12 the uveitis had reached its peak $(4+)$. All four guinea pigs in Group 2 (S-antigen alone) had signs of uveitis on day 12 and the severity of inflammation had reached its maximum $(4+)$ by day 14 (Table III). At the peak of the inflammatory response the eyes showed congestion, corneal haze, cells and flare in the anterior chamber, hyperaemia of the iris, haemorrhagic retro-iridial hypopyon and vitreous exudate obscuring retinal details.

Ocular pathology: Eyes from all guinea pigs, both treated and untreated with S2.4.C5 showed similar features on histology. The lesions within an eye ranged from early inflammatory infiltration in the choroid with some disruption of the subjacent photoreceptor layer (Fig. 1a) to massive infiltration of the entire chorioretina, optic nerve, ciliary body and iris (Fig. 1b). The choroid was thickened with inflammatory cells, chiefly lymphocytes, monocytes, polymorphonuclear leukocytes and macrophages. The retinal pigment epithelium was disrupted at places with loss of the photoreceptor layer. The retina showed serous detachment at places with a predominance of neutrophils and monocytes in the exudate. At other places the retinal architecture was totally disorganised making it impossible to distinguish the various layers.

Pineal inflammation: The pineal glands of all animals in both groups showed massive mononuclear infiltration. In some glands it was largely confined to the subcapsular zone but in most it was uniformly spread throughout the substance of the gland (Fig. 1c) disrupting the normal architecture (Fig. 1d). In contrast to the ocular inflammation the pineal inflammatory response was predominantly lymphocytic with an absence of polymorphonuclear cells.

\section{Rats}

Clinical: Five of the six control animals (Group 2, immunised with S-antigen alone) developed a severe early onset uveitis involving the anterior and posterior segments of both eyes. Clinically this was manifest as a hypopyon uveitis with obscuration of the fundal view at its peak of inflammation. Similarly, five of the six rats immunised with Santigen and non-specific IgG (Group 3) developed a marked uveitic response although this was slightly reduced in severity with a later onset. In contrast, only two of ten rats that were immunised with S-antigen and the rat monoclonal antibody S2.4.C5 developed uveitis, in each case uveitis was also delayed in onset and of least severity.

Ocular pathology: Eyes from S-antigen immunised rats treated with the monoclonal antibody S2.4.C5 which were clinically not inflamed $(80 \%)$ showed no evidence of inflammatory cell infiltration (Fig. 2a). In contrast, eyes from untreated rats or rats treated with non-specific IgG demonstrated multiple focal inflammatory lesions which varied in severity from perivasculitis with early round cell infiltration in the photoreceptor layer (Fig. 2b) to extensive granulomatous infiltration of the retina and choroid with loss of photoreceptor cells (Fig.

Table III Uveitic and pinealitic response to $S$-antigen

\begin{tabular}{lrrrrr}
\hline & \multicolumn{2}{c}{ Guinea pigs $^{\text {Group }^{*}}$} & \multicolumn{3}{c}{ Rats $^{*}$ Group $^{*}$} \\
& 1 & 2 & 1 & 2 & 3 \\
\hline Total number of animals & 5 & 4 & 10 & 6 & 6 \\
Number with uveitis & 5 & 4 & 2 & 5 & 5 \\
Number with pinealitis & 5 & 4 & 10 & 5 & 5 \\
Severity (mean)@ & 4 & 4 & 1 & 3 & 2 \\
Day of onset@ & 10 & 12 & 19 & 14 & 19 \\
\hline
\end{tabular}

* 1. S2.4.C5 treated, 2. Untreated, 3. Rat IgG treated.

@Of uveitis. 

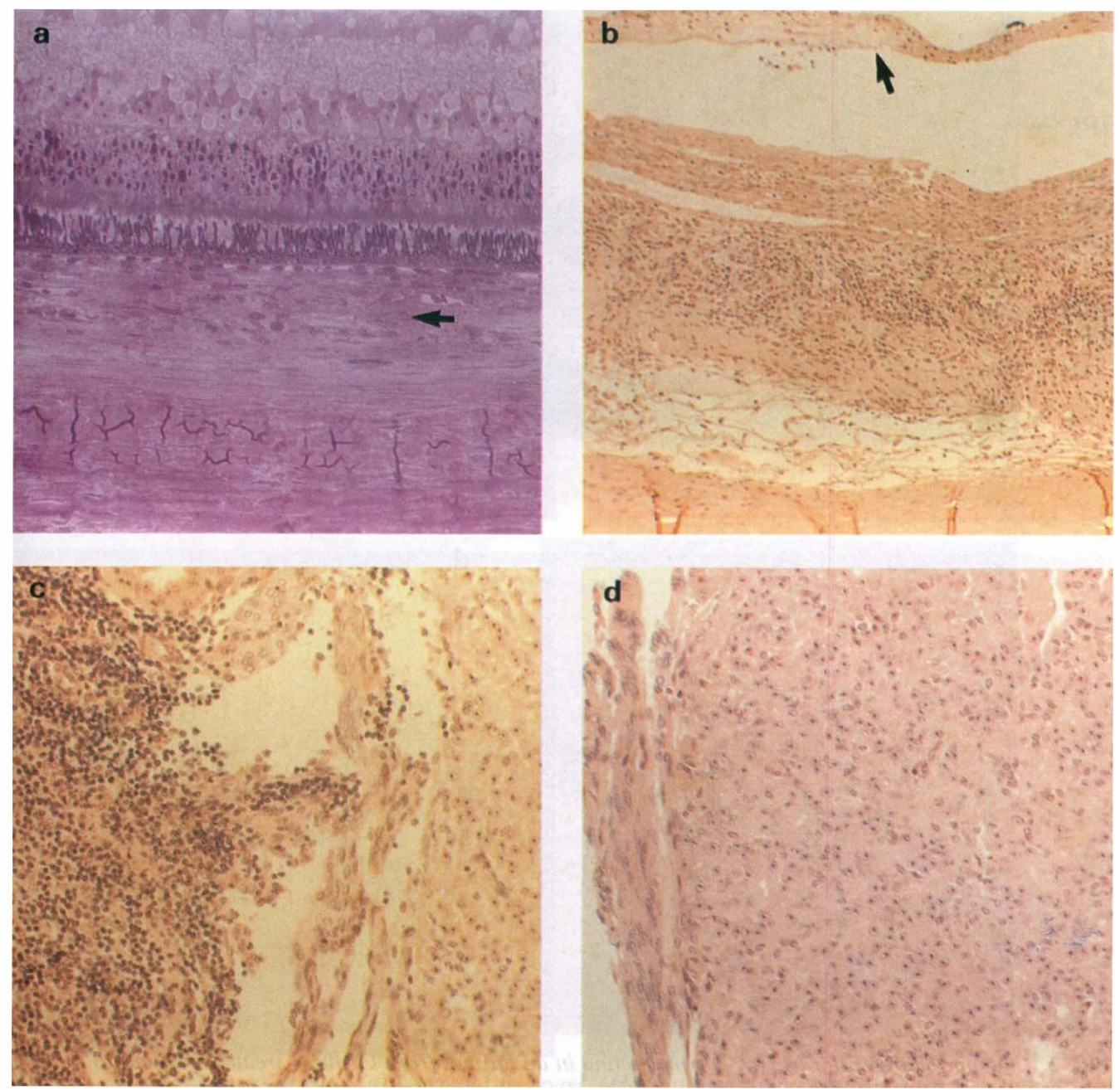

Fig. 1. Ocular changes in guinea pigs (a) Early choroidal lesion (arrow) showing inflammatory cell infiltration around vessels with thickening of the choroid, in an animal from the control group. (Toluidine blue and basic fuschin $\times 220$ ). (b) Advanced lesion showing a grossly thickened choroid packed with inflammatory cells, loss of photoreceptors and an atrophic retina (arrow) in an animal from the group treated with S2.4.C5. (Haematoxylin and eosin $\times 85)$. Pineal changes in guinea pigs (c) Dense mononuclear cell infiltration in the pineal gland of an animal treated with S2.4.C5 (Haematoxylin and eosin $\times 200)$. (d) Normal guinea pig pineal (Haematoxylin and Eosin $\times 200)$.

2c) as described previously for Lewis rats. ${ }^{16}$ In most cases, retinal damage was severe and was characterised by a cellular infiltrate consisting of monocytes, macrophages, lymphocytes and a few neutrophils. Similar cells infiltrated the choroidal layer. Immunocytochemical staining of the cell infiltrate indicated that a high proportion of the cells were monocytes/macrophages (Fig. 2d) and CD4 positive cells. CD8 positive cells were less common while there were few B cells. The proportions of cells were the same irrespective of the site of the lesion eg. around retinal vessels, in the photoreceptor layer or in the choroid. Many cells in the focal lesions expressed Ia antigen but were negative for interleukin 2 receptor.

Pineal Inflammation: Pinealitis was pre- 

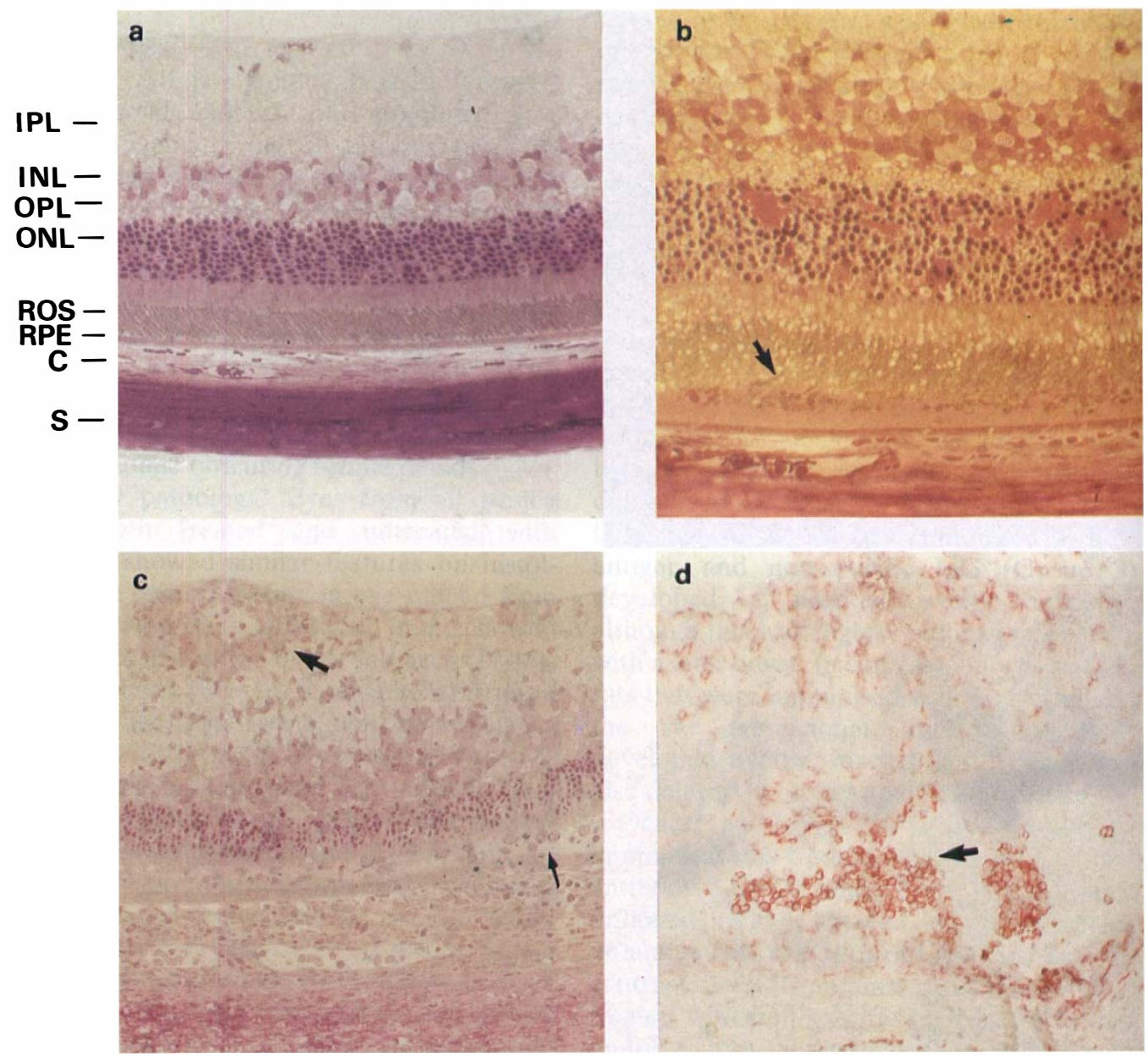

Fig. 2. Ocular changes in rats. (a) Normal retina in an animal from Group 1 treated with anti-S monoclonal antibody S2.4.C5. The rod outer segments (ROS) are well preserved. IPL, inner plexiform layer; $I N L$, inner nuclear layer; $O P L$, outer plexiform layer; $O N L$, outer nuclear layer; RPE, retinal pigment epithelium; C, choroid; $S$, sclera. (Toluidine blue and basic fuschin, $\times 280$ ). (b) Early lesion. Showing round cell infiltration in the photoreceptor layer (arrow) with vacuolation and disruption of the rod outer segments. (Toluidine blue and basic fuschin, $\times 350$ ). (c) Advanced lesion. Showing perivascular infiltration (thick arrow), loss of photoreceptor layer with subretinal infiltration (thin arrow) and a thickened choroid packed with inflammatory cells. (Toluidine blue and basic fuschin, $\times 200$ ). (d) Subretianal exudate showing predominantly cells that are stained by the monocyte/macrophage monoclonal marker (EDI, arrow). Note absence of photoreceptor layer. (Alkaline phosphatase-Antialkaline phosphatase (APAAP) $\times 100$ ).

sent in all three groups of S-antigen immunised rats whether untreated or treated with either rat $\mathrm{IgG}$ or the monoclonal antibody S2.4.C5 (Figs 3b and c). Two rats (one from each of the control group) that failed to develop EAU did not show any pineal inflammation either (Fig. 3a). Pinealitis in all groups occurred as a mild to moderate subcapsular focal granuloma, frequently close to the pineal stalk. Perivasculitis was a common feature and the predominant cells were lymphocytes and monocytes. Immunocytochemically, CD4 cells were scattered throughout the gland (Fig. 3d) with monocytes and CD8 

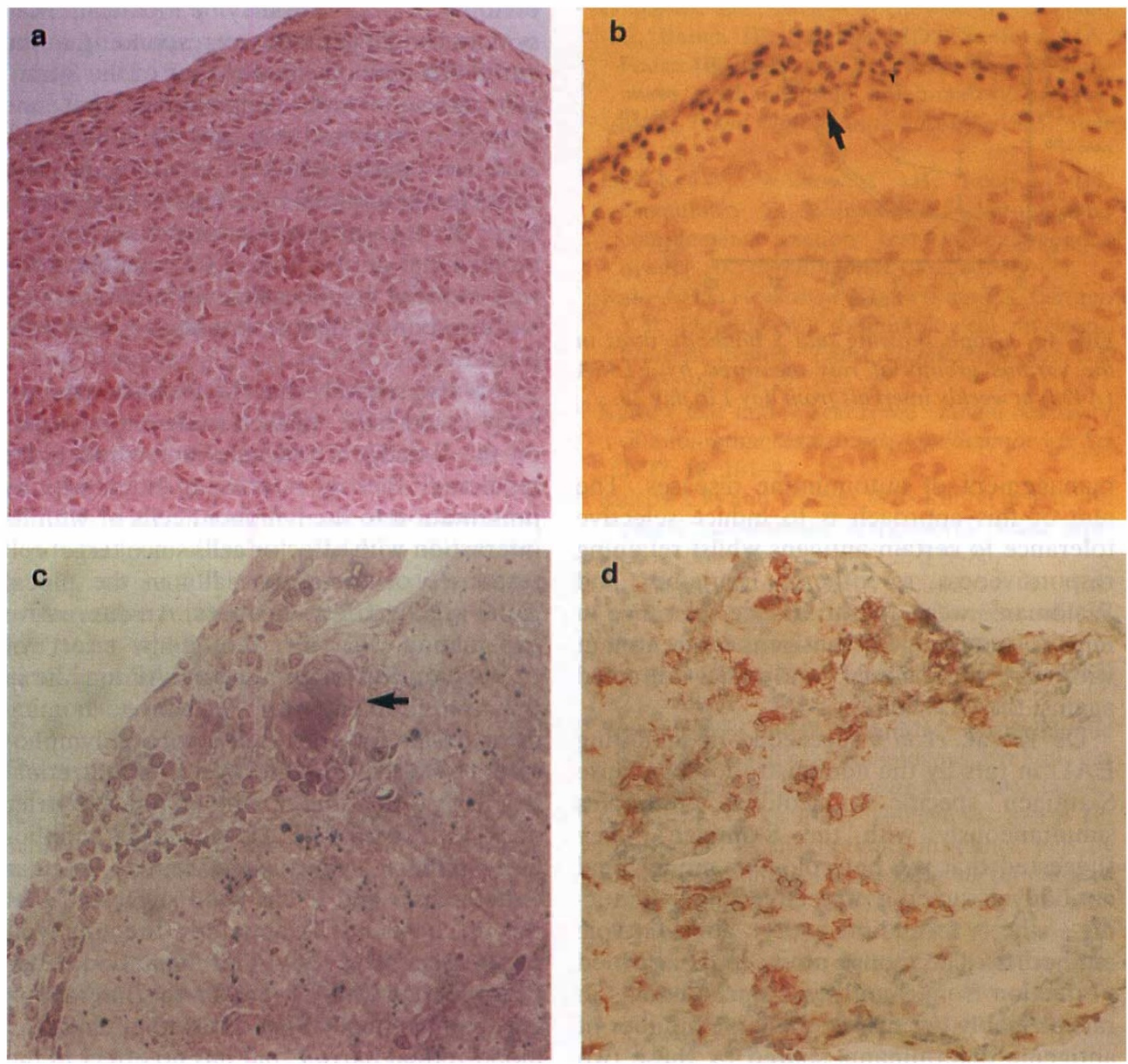

Fig. 3. Pineal changes in rats. (a) Normal rat pineal. (Haematoxylin and eosin $\times 200$ ). (b) Subcapsular focal granulomatous infiltration. (arrow, Haematoxylin and eosin $\times 200$ ). (c) Perivasculitis (arrow) with subcapsular infiltration. (Toluidine blue and basic fuschin $\times 450$ ). (d) Inflammatory infiltration in the pineal stalk region showing predominantly cells that are stained by the T-helper cell monoclonal marker CD4 (W3-27). (APAAP ×350).

cells next in frequency. A few B cells were also noted. The relative proportions of cells in inflammatory lesions was the same for all three groups of rats. Ia antigen expression was a common feature, as expected, but cells expressing interleukin 2 receptor were not observed.

\section{Humoral response to $S$-antigen}

Untreated and IgG treated rats which were immunised with bovine $\mathrm{S}$-antigen showed a progressive increase in anti-S antibodies by
ELISA between 7 and 21 days post immunisation (Fig. 4). Rats treated with monoclonal antibody S2.4.C5 consistently showed higher levels of anti-S antibodies in their serum than untreated or IgG treated controls (Fig. 4). After 21 days antibody levels were maximal for all three groups.

\section{Discussion}

Modulation of the host immune response using monoclonal antibodies, although still experimental, has great potential value in the 
ANTI-S ANTIBODY TITRES IN THE DIFFERENT GROUPS OF RATS

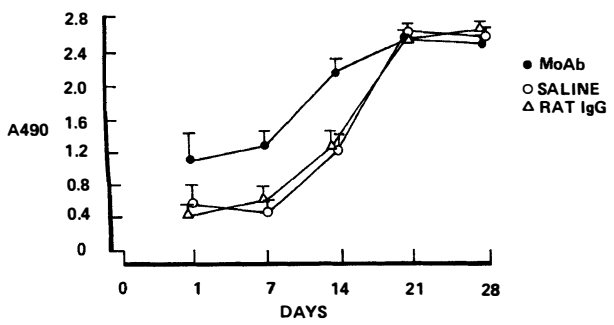

Fig. 4. Graph showing anti-S antibody titres in the various groups of rats measured by ELISA (A490) at weekly intervals from day 1 to day 28.

management of autoimmune diseases. The aim of this approach is to induce selective tolerance to certain antigens whilst retaining responsiveness to others. Benjamin and Waldman ${ }^{25}$ were able to induce tolerance in mice to immunogenic antigens by treatment with rat monoclonal antibodies directed against the CD4 cells.

De Kozak et $a l^{19}$ succeeded in inhibiting EAU in rats by the administration of mouse S-antigen specific moncolonal antibodies simultaneously with the S-antigen. They suggested that the heterologous monoclonal antibody assumed a protective role by inducing the formation of anti-idiotypic antibodies. The mouse monoclonal afforded protection from S-antigen induced uveitis in rats probably because of the large number of antigenic determinants shared by these two species of rodents. However, the heterologous system that we used demonstrated that the protective role of the S-antigen specific monoclonal antibody, S2.4.C5, does not extend far across species. All the guinea pigs that received S2.4.C5 along with S-antigen developed a severe uveitis and pinealitis. The onset of uveitis was two days earlier than in the control group indicating that the monoclonal may have in fact acted like an adjuvant. On the other hand, our homologous system using a rat monoclonal antibody in rats, was extremely effective in inhibiting EAU. Interestingly this contrasted with the observation that S2.4.C5 was not effective in inhibiting the pineal inflammation in rats. Recent evidence presented by Donoso et a ${ }^{26}$ indicates that EAU and EAP inducing epitopes of S-antigen may be identical. They synthesised 23 peptides corresponding to the entire 404 amino acid sequence of the S-antigen molecule and demonstrated that one peptide nominated peptide M (18 amino acids in length) was highly pathogenic and consistently induced EAU and EAP in Lewis rats. If the protection provided by the monoclonal antibody S2.4.C5, against EAU was induced by idiotype anti-idiotype network responses then it should also have inhibited EAP.

It is also unlikely that the monoclonal antibody could have masked antigenic epitopes on the S-antigen molecule in the rod outer segments ${ }^{27}$ thereby interfering either with its presentation to the lymphoid cells or with its interaction with effector cells since target cell responses occurred normally in the pineal gland in S2.4.C5 treated rats. An alternative explanation for the inhibitory effect of S2.4.C5 on EAU but not on EAP may lie in the requirement for effective homing mechanisms for sensitised cytotoxic lymphocytes. Whereas, in the eye a blood-retinal barrier is well defined, a blood pineal barrier does not exist. ${ }^{28}$ In EAU sensitised lymphocytes adhere to activated retinal vascular endothelium and it has been suggested that this mechanism is essential for directing lymphocyte traffic to sites of inflammation. ${ }^{29}$ It is possible that S2.4.C5 inhibits this interaction between lymphocytes and endothelium at the blood-retinal barrier, but has no effect in the barrier-free pineal, gland where the vascular endothelium is fenestrated. ${ }^{30,31}$

The presence of relatively higher levels of antibodies during the first two weeks of immunisation in S2.4.C5 treated animals is of interest. Although the fate of the monoclonal antibody after inoculation in the rats is not known, some of this anti-S activity was probably due to the inoculated monoclonal antibody in the early stage. After one week it is probable that much of the injected monoclonal antibody had been degraded or processed. In a heterologous system, de Kozak et $a l^{20}$ inoculated rats with a mouse anti-S monoclonal antibody and failed to detect its presence in the sera after one week, although in the present homologous system experiment, some of the monoclonal antibody may 
have persisted for longer periods. In subsequent weeks, particularly the third and fourth weeks post-immunisation, anti-S titres were equally raised in all groups. At this stage the polyclonal host-response to S-antigen would have predominated and was clearly not related to induction of tolerance and disease prevention as it was similar in all groups of animals.

Whatever the mechanism, it is clear that monoclonal antibody S2.4.C5 is highly effective in abrogating EAU and this result raises the possibility of similar strategies being adopted in human disease. There are, however, many problems which will have to be overcome not least of which is identifying patients with chronic intraocular inflammation who have clear cut evidence of autoimmunity to retinal antigens. For this to be achieved we must await appropriately sensitive tests which will differentiate 'natural' autoimmunity from pathological autoimmune phenomena. ${ }^{32}$

This work was supported by a Research Grant from the Grampian Health Board, Aberdeen, Scotland. We thank Mrs Karen Hercus, for preparing the purified S-antigen and Miss DM Reid for preparing the hybridoma cell line for the monoclonal antibody.

\section{References}

${ }^{1}$ Rahi AHS and Garner A: Immunopathology of the eye. London. Blackwell Scientific, 1976: 155.

2 James DG, Friedmann AI, Bowden PMA, Bowden AN: Uveitis report of a five year survey. Postgrad Med J 1969, 45: 622-6.

${ }^{3}$ Perkins ES: Uveitis survey at the Institute of Ophthalmology, London. In Aronson SB ed. Clinical Methods in Uveitis. London. Mosby, 1968: 48.

${ }^{4}$ Witmer R: Uveitis survey at the Institute of Ophthalmology, London. In Aronson SB ed. Clinical Methods in Uveitis. London. Mosby, 1968: 48.

${ }^{5}$ Aronson SB, Yamamoto E, Goodner E, O'Connor GR: The occurrence of an auto anti-uveal antibody in human uveitis. Arch Ophthalmol 1964, 72: 621-5.

${ }^{6}$ Dumonde DC, Kasp-Grochowska E, Graham E, Sanders MD, Faure JP, de Kozak Y, Tuyen VV: Anti-retinal autoimmunity and circulating immune complexes in patients with retinal vasculitis. Lancet. 1982, 9: 787-92.
${ }^{7}$ Dumonde DC, Kasp-Grochowska E, Graham E, Banga JP, Sanders MD, Stanford MA, Faure JP, de Kozak Y, Tuyen VV: Autoimmune mechanisms in inflammatory eye disease. Trans Ophthalmol Soc UK 1985, 104: 232-8.

${ }^{8}$ Hallet JW, Wolkowicz MI, Leopold IH, Canamucio C, Wijewski E: Autoimmune complement fixation test in endogenous uveitis. Arch Ophthalmol 1962, 68: 168-71.

${ }^{9}$ Rahi AHS, Holborow EJ, Perkins ES, Gurgen YY, Dinning WJ: Immunological investigations in uveitis. Trans Ophthalmol Soc UK 1976, 96: 113-22.

${ }^{10}$ Kalsow CM and Wacker WB: Pineal reactivity of anti-retina sera. Invest Ophthalmol Vis Sci 1977, 16: 181-4.

${ }^{11}$ Kalsow CM and Wacker WB: Rabbit ocular and pineal autoimmune response to retina antigens. Curr Eye Res 1986, 5: 579-86.

${ }^{12}$ Mochizuki M, Charley J, Kuwabara T, Nussenblatt RB, Gery I: Involvement of the pineal gland in rats with experimental autoimmune uveitis. Invest Ophthalmol Vis Sci 1983, 24: $1333-8$.

${ }^{13}$ Wacker WB and Lipton MM: Experimental allergic uveitis: homologous retina as uveitogenic antigen. Nature 1965, 206: 253-4.

${ }^{14}$ de Kozak Y, Usui M, Thillaye B, Faure JP: Induction of uveoretinitis in guinea pigs by immunisation against autologous retina. Exp Eye Res 1976, 22: 289-90.

${ }^{15}$ de Kozak Y, Thillaye B, Renard G, Faure JP: Hyperacute form of experimental autoimmune uveoretinitis in Lewis rats. Electron microscopic study. Graefes Arch Ophthalmol 1978, 208: 135-42.

${ }^{16}$ de Kozak Y, Sakai J, Thillaye B, Faure JP: $S$ antigen-induced experimental autoimmune uveo-retinitis in rats. Curr Eye Res 1981, 1: $327-37$.

${ }^{17}$ Forrester JV and Borthwick GM: Clinical relevance of S-antigen induced experimental uveoretinitis. Trans Ophthalmol Soc UK 1984, 103: 497-502.

${ }^{18}$ Forrester JV, Borthwick GM, McMenamin PG: Ultrastructural pathology of S-antigen uveoretinitis. Invest Ophthalmol Vis Sci 1985, 26: 1281-92.

${ }^{19}$ de Kozak Y, Mirshahi M, Boucheix C, Faure JP: Inhibition of experimental autoimmune uveoretinitis in rats by S-antigen specific monoclonal antibodies. Eur J Immunol 1985, 15: $1107-11$

${ }^{20}$ de Kozak Y, Mirshahi M, Boucheix C, Faure JP: Prevention of experimental autoimmune uveoretinitis by active immunisation with 
autoantigen-specific monoclonal antibodies. Eur J Immunol 1987, 17: 541-7.

${ }^{21}$ Dua HS, Sewell HF, Forrester JV: The effect of retinal S-antigen specific monoclonal antibody therapy on experimental autoimmune uveoretinitis and experimental autoimmune pinealitis. Clin Expt Immunol (In Press).

22 Reid DM, Loeffler KU, Campbell AM, Forrester JV: Electron immunocytochemical localisation of retinal S-antigen with a rat monoclonal antibody. Exp Eye Res 1987, 45: 731-45.

${ }^{23}$ Al-Mahdawi S, Forrester JV, Lee WR: A simplified method for the isolation of highly purified bovine retinal S antigen. J Neuroimmunol 1987, 14: 99-108.

${ }^{24}$ Forrester JV, Stott DI, Hercus KM: Naturally occurring antibodies to bovine and human retinal S-antigen: A comparison between uveitis patients and normal healthy volunteers. Br J Ophthalmol (In press).

${ }^{25}$ Bejamin $\mathrm{RJ}$ and Waldmann $\mathrm{H}$ : Induction of tolerance by monoclonal antibody therapy. Nature 1986, 320: 449-51.

${ }^{26}$ Donoso LA, Merryman CF, Sery TW, Shinohara T, Dietzschold B, Smith A, Kalsow CM: S-antigen: characterisation of a pathogenic epitope which mediates experimental autoimmune uveitis and pinealitis in Lewis rats. Curr Eye Res 1987, 6: 1151-9.
${ }^{27}$ Hutchinson IV: Antigen-reactive cell opsonization (ARCO) and its role in antibodymediated immuno-supression. Immunol Rev 1980, 49: 167-97.

${ }^{28}$ Lee JC: Anatomy of the blood-brain barrier under normal and pathological conditions. In Haymaker W, Adams RD eds. Histology and Histolopathology of the nervous system. Vol 1 Springfield, Illinois: Charles C Thomas 1982: 798.

${ }^{29}$ Lightman S, Caspi R, Nussenblatt R: Increased accumulation in the eye of an ocular antigenspecific $\mathrm{T}$-cell line when endothelial cells express Ia. Abstract, British Society for Immunology Workshop, London, November 1987: 141.

${ }^{30}$ Milofsky AH: The fine structure of the pineal in the rat, with special reference to parenchyma. Anat Rec 1957; 127: 435.

${ }^{31}$ Wolfe DE: The epiphyseal cell: An electronmicroscopic study of its intercellular relationships and intracellular morphology in the pineal body of the albino rat. Prog Brain Res 1965; 10: 332-86.

${ }^{32}$ Forrester JV, Liversidge J, Towler H, Hercus $\mathrm{K}$, Urbaniak S: Does autoimmunity play a role in human uveitis. Excerpta Medica (Amsterdam) (In press). 